ISSN: 2146-3042

DOI: 10.25095/mufad.756266

\title{
Jeopolitik Risk ve Borsa Endeksinin Nedensellik Analizi: Gelişmekte Olan Ülkeler Üzerine Bootstrap Panel Nedensellik Testi*

\section{$\ddot{O Z E T}$}

Jeopolitik risk, ekonomik belirsizlik ve siyasi belirsizlik, ekonomide yol açtıkları olumsuz etkilerden dolayı "belirsizlik üçlüsü” olarak anılmaktadır. Jeopolitik risk unsuru sadece yerel terör saldırılarının değil, aynı zamanda savaş riskleri, askeri tehditler ve Orta Doğu gerginlikleri gibi tüm küresel belirsizlikleri kapsamaktadır. Jeopolitik riskler yatırım kararlarının belirleyicilerinden biri olması nedeniyle tüm finansal piyasaları etkilemektedir. Yüksek jeopolitik riskin borsa endeksinde düşüs, yabancı sermayenin ülkeden çıkışı, ekonomik faaliyet hacminde daralma şeklinde siralanacak makro ve mikro ölçekli pek çok olumsuz etkisinden bahsedilmektedir. Jeopolitik riskin etkilerini ampirik olarak test etmeye yönelik çalışmaların sayısı ise oldukça sınırlıdır. Bu durumun en temel nedeni, jeopolitik riskin ölçümüne yönelik tutarlı bir göstergenin olmayışından kaynaklanmaktadır. Caldara ve Iacoviello (2016), ABD, Ingiltere ve Kanada'da basılan 11 gazetenin arşivlerini tarayarak ülkeler arası savaș, terörist atak ve askeri gerilimleri konu eden haberlerin sayımın yapmışlar ve 1985 yll Ocak ayından başlamak üzere jeopolitik risk ölçütünü (Geopolitical Risk-GPR) geliștirmişlerdir. Bu çallşma Arallk 1987-Ağustos 2018 döneminde 9 gelişmekte olan ülkede Caldara ve Iacoviello (2016) jeopolitik risk ölçütü ve borsa endeksi arasında nedensellik ilişsisinin varlığını araştırmaktadır. Bu amaçla her bir ülke için bootstrap ve Wald istatistiğinin hesaplandiğı SUR sistemine dayalı bir yöntem olan Kónya (2006) panel nedensellik testi uygulanmıştır. Elde edilen ampirik bulgular Arjantin, Brezilya, Meksika ve Tayland'da jeopolitik riskten borsa endeksine doğru tek yönlü nedensellik olduğunu göstermiştir.

Anahtar Kelimeler: Jeopolitik Risk, Borsa Endeksi, Kónya (2006) Bootstrap Panel Nedensellik Testi.

JEL Sinıflandirmast: C58, C33.

\section{Causality Analysis of Geopolitical Risks and Stock Market Indices: A Bootstrap Panel} Causality Test on Developing Countries

\section{ABSTRACT}

Geopolitical risk, economic uncertainty and political uncertainty are referred to as the "triangle of uncertainty" due to the negative effects they have caused in the economy. The geopolitical element of risk includes not only local terror attacks, but also all global uncertainties such as war risks, military threats and Middle Eastern tensions. Geopolitical risks affect all financial markets as they are one of the determinants of investment decisions. High geopolitical risk has many macro-and micro-scale negative impacts on the stock market indices, the outflow of foreign capital and the reduction in the volume of economic activity. However, the number of studies to empirically investigate the effects of the geopolitical risk is quite limited. The main reason for this situation is the lack of a consistent indicator for the measurement of geopolitical risks. Caldara and Iacoviello (2016) have scanned the archives of 11 newspapers published in the US, UK and Canada, counting news on war between countries, terrorist attacks and military tensions, and developed Geopolitical Risks (GPR) criteria starting from January 1985. This paper investigates the possibility of causality between Caldara and Iacoviello (2016) geopolitical risks (GPR) and stock index in 9 developing countries in the period of December 1987-August 2018. To this aim, Kónya (2006) panel causality test based on SUR system is applied in which country bootstrap critical values and Wald statistics are obtained. The results indicate one-way causality from geopolitical risks $(G R P)$ to stock market indices in Argentina, Brazil, Mexico, and Thailand.

Keywords: Geopolitical Risk, Stock Market Indices, Kónya (2006) Bootstrap Panel Causality Test.

Jel Classification: C58, C33.

\footnotetext{
* Makale Gönderim Tarihi: 10.8.2019, Makale Kabul Tarihi: 28.11.2019, Makale Türü: Nicel Araştırma

* Doç.Dr., Ahi Evran Üniversitesi İktisadi ve İdari Bilimler Fakültesi, gulbahar.ucler@ahievran.edu.tr, ORCID ID: 0000-0002-5872-8577.

** Doç.Dr., Necmettin Erbakan Üniversitesi Siyasal Bilgiler Fakültesi, sozsahin@erbakan.edu.tr.
} 


\section{GíRiş}

Sermaye ve finans piyasalarının küresel piyasalarda yaşanan ekonomik, siyasi ve jeopolitik gelişmelerden etkilenen dinamik yapısı, borsada risk yönetimine çok önemli bir işlev yüklemektedir. Risk kavramı beklentiler dışında gelişen ve sonucunda olumlu veya olumsuz bir duruma yol açan olay olarak tanımlanmaktadır. Diğer bir tanıma göre ise risk, kazanma veya kaybetmede ortaya çıkan belirsizliktir (Aksoy ve Tanrı̈ven; 2013; 33). Riskler, etkileme alanına göre sistematik ve sistematik olmayan riskler olarak ikiye ayrılmaktadır. Sistematik olmayan riskler finansal sistemin sadece belirli bir kısmını etkileyen, müdahale edilebilir ve önlenebilir risklerden oluşurken sistematik riskler; önceden tahmin edilemeyen, ortadan kaldırılması mümkün olmayan ve tüm finansal piyasaları ve yatırımcıları aynı anda etkileyebilmektedir. 2016 yılında Deloitte tarafindan yapılan Avrupa CFO araştırmas ${ }^{1}$, Avrupa genelinde önümüzdeki yıllarda öne çıkacak risklerin bilançosunu ortaya koymaktadır. Rapora göre, jeopolitik riskler önümüzdeki dönemde finans sektörünü olumsuz etkileyecek faktörlerin başında gelmektedir. Yine Avrupa Merkez Bankası Nisan 2017 Ekonomik Bülteni ${ }^{2}$ ve IMF Ekim 2017 Dünya Ekonomik Görünüm Raporu ${ }^{3}$, jeopolitik belirsizliklerin ekonomik görünüm açısından önemli bir risk olduğunu ortaya koymaktadır. 2018 Küresel Riskler Raporu ${ }^{4}$ için yapılan Ylllık Küresel Riskler Algl Anketi'nde ${ }^{5}$ ise önümüzdeki dönemlerin yüksek risk altında geçeceğine yönelik sonuçlar rapor edilmektedir. $\mathrm{Bu}$ ankette, 1.000 katılımcıya 2018 yılında yaşanacak risk eğilimleri hakkında görüşleri sorulmuştur. Yanıtların \%59'u risklerin artacağı, \%7'si ise risklerin azalacağı yönündedir. Katılımciların \%93'ü ise küresel arenada yer alan büyük oyuncular arasındaki siyasi veya ekonomik cepheleşmelerin daha da kötüleşmesini beklemektedirler.

Riskin ekonomik göstergeler üzerine etkisini araştıran mevcut literatür çalışmaları çoğunlukla risk unsurlarından sadece biri olan terörist atakların finansal piyasalar ve borsa getirilerine etkisi üzerine yoğunlaşmıştır. Bu çalışma ülkelerarası ilişkilerin normal seyrini etkileyen savaş, terör faaliyetleri, gerilim gibi risk unsurları dikkate alması yönüyle daha kapsamlı bir jeopolitik risk ölçümü sunan Caldara ve Iacoviello (2016) jeopolitik risk ölçütünü (GPR) kullanması yönüyle mevcut çalışmalardan farklılaşmakta ve bu anlamda literatüre katkı sağlamayı amaçlamaktadır. Ayrıca nedensellik ilişkisini araştırmak üzere yatay kesit bağımsızlı̆̆ını varsayan geleneksel yöntemler yerine yatay kesit bağımlılı̆̆ını ve panelin heterojen yapısını dikkate alan Kónya (2006) yönteminin kullanılması da bu çalışmayı mevcut literatürden farklı kılmaktadır.

Jeopolitik risk ve borsa endeksi arasındaki ilişkinin incelendiği bu çalışma dört bölümden oluşmaktadır. Girişin ardından ikinci bölümde teorik çerçeve ve literatür taramasına yer verilecek, üçüncü bölümde ise veri seti ve ampirik model hakkında açıklamalar yapılacaktır. Kullanılan ekonometrik yönteme ilişkin bilgilerin sunulduğu ve ulaşılan bulguların yorumlandığı dördüncü bölümün ardından genel bir değerlendirme ile çalışma tamamlanmaktadır.

\footnotetext{
${ }^{1}$ Europen CFO Survey, Politics takes centre stage Q1/May 2016. www.DeloitteResearchEMEA.com

${ }^{2}$ ECB, Economic Bulletin Issue 4/2017

${ }^{3}$ IMF World Economic Outlook, October 2017.

${ }^{4}$ The Global Risks Report 2018

${ }^{5}$ Anket kapsamında görüşlerine başvurulan bin katılımcıya 2018 yılında yaşanacak risk eğilimleri sorulmuştur.
} 


\section{TEORİK ÇERÇEVE VE LITERATÜR TARAMASI}

Jeopolitik riskler yatırım kararlarının belirleyicilerinden biri olması nedeniyle tüm finansal piyasaları etkilemektedir. Jeopolitik risk unsuru sadece yerel terör saldırılarının değil, aynı zamanda savaş riskleri, askeri tehditler ve Orta Doğu gerginlikleri gibi tüm küresel belirsizlikleri kapsamaktadır. Politik istikrarsızlıklar, siyasi rejim değişiklikleri, mali çöküşler, doğal afetler, savaşlar, askeri çatışmalar ve terörist tehditler gibi kalıcı jeopolitik gerginlikler bölgenin jeopolitik risk oranını yükseltmektedir. Jeopolitik gerginliklerin nispeten daha güçlü ve daha kalıcı olduğu ülkelerde bu risklerin, yatırım kararları ve temel finansal varlıkların performansı üzerindeki etkisinin daha şiddetli olacağı yönünde kanıtlar vardır. Yapılan çalışmalar, jeopolitik belirsizliklerin hem hisse senedi getirilerini ve volatiliteyi etkileme eğiliminde olduğuna hem de gelişmekte olan ekonomilerden gelişmiş ekonomilere doğru bir sermaye çıkışına neden olduğuna dair bulgular sunmaktadır (Zussman ve Zussman; 2006, Drakos; 2010, Karolyi ve Martell; 2010, Abadie ve Gardeazabal; 2008, Kollias vd.; 2011, 2013, Balcılar vd.; 2016). Literatürde yer alan bazı çalışmalara göre savaşlar, silahlı çatışmalar ve terörizm gibi güvenlik şokları finansal piyasalardaki getiri ve volatilite üzerinde önemli bir etkiye sahiptir. Ancak bu etkiler, tahvil ve hisse senedi piyasalarında ve ülkeler genelinde heterojen bir yapı sergilemektedir. Aslam ve Kang (2015) terörist saldırıların Pakistan hisse senedi getirileri üzerinde kısa süreli ve negatif bir etkiye sahip olduğunu ancak etki yoğunluğunun saldırı yerlerine ve türlerine göre farklılık gösterdiğini söylemektedirler. Balcılar, Cerci ve Demirer (2016) terör saldırılarının G7 ülkelerinde hisse senedi piyasası getirileri ve volatilitesine olan etkilerini inceledikleri çalışmalarında, terör saldırılarının piyasa getirileri üzerinde önemli etkileri olduğunu göstermesine rağmen sadece Japonya ve İngiltere'de volatilite üzerinde etkili olduğu sonucuna ulaşmışlardır. Arin, Ciferri ve Spagnolo (2008), terörizmin altı ülkenin (Endonezya, İsrail, İspanya, Tayland, Türkiye ve İngiltere) finansal piyasaları üzerindeki etkisini inceledikleri çalışmalarında, terörün finansal piyasanın volatilitesi ve getirileri üzerinde olumsuz bir etkiye sahip olduğu sonucuna varmışlardır. Ayrıca çalışmada, terör şoklarının etkisinin ülkeler arasında farklılık gösterdiği ve gelişmekte olan pazarlarda etkisinin daha yüksek olduğu vurgulanmaktadır. Karolyi ve Martell (2010) ABD'de 75 terörist saldırının kamuya açık firmaların hisse senedi getirileri üzerindeki etkisini inceledikleri çalışmalarında, sekiz yıllık bir süre içerisinde gerçekleşen terörist saldırıların hisse senedi fiyatları üzerinde yaklaşık olarak \%0.83 oranında negatif yönde ve istatistiksel olarak anlamlı bir etkisinin olduğu yönünde sonuçlar elde etmişlerdir. Bu bulgulara göre negatif etki, piyasada her firmanın piyasa kapitalizasyonu başına ortalama 401 milyon \$'lık bir zarara eşittir. Çalışmada ayrıca bu saldırıların etkilerinin ülkeden ülkeye farklılık gösterdiği, daha zengin ve daha demokratik ülkelerde bu tarz terörist saldırıların negatif fiyat reaksiyonlarının daha büyük olduğu ve artan jeopolitik risk nedeniyle kaybedilen beşeri sermaye faktörünün fiziksel kayıplardan daha büyük ve daha önemli olduğu vurgulanmaktadır. Balcılar vd. (2018) jeopolitik risklerin BRICS ülkeleri hisse senedi getirileri üzerine etkilerini inceledikleri çalışmalarında, jeopolitik gerginliklere ilişkin göstergelerin analize dahil edilen ülke grubu üzerindeki etkilerinin heterojen olduğu yönünde bulgular elde etmişlerdir. Çalışmadan elde edilen diğer sonuçlara göre, jeopolitik riskler hisse senedi getirilerinden ziyade piyasadaki volatilite üzerinde daha büyük bir etkiye sahiptir. Jeopolitik risklere maruz kalan piyasaların dalgalanma olasılığı artmaktadır. Çalışmadan elde edilen diğer bir bulguya göre ise, incelenen ülkeler içerisinde Rusya hem hisse senedi getirisi 
hem de volatilite açısından jeopolitik risklerden en çok etkilenen ülke iken Hindistan BRICS ülkeleri arasında jeopolitik risk şoklarına en dirençli ülke olarak bulunmuştur.

Ancak literatürdeki bazı çalışmalar, geleneksel finansal piyasaların genelinin jeopolitik risklerin olumsuz etkilerine karşı bağışıklı̆ının olmadığını savunmaktadırlar. (Chen ve Siems, 2004; Charles ve Darne, 2006). Bouri vd. (2018)'nin jeopolitik risklerin İslami sermayenin ve tahvil piyasalarının getiri ve volatilite dinamikleri üzerindeki nedensellik etkilerini inceledikleri çalışmalarında, jeopolitik risklerin genel olarak getirilerden ziyade volatiliteyi etkilediği yönünde kanttlar elde etmişlerdir. Bununla birlikte çalışmadan elde edilen bulgular, jeopolitik risklerin İslami sermayenin hem getiri hem de volatilite ölçümlerini öngörebildiği yönündedir. Çalışmanın sonucunda İslami finansal araçların da jeopolitik risklerden geleneksel piyasalar kadar etkilendiği ve dolayısıyla jeopolitik belirsizlik risklerini ortadan kaldırmak için kullanılamayacağı ve İslami hisse senedi ve tahvil piyasalarının da jeopolitik olaylara karşı zayıf kaldığı vurgulanmaktadır.

Kollias, Papadamou ve Stagiannis (2010), İsrail'in 2008-2009'da Gazze askeri saldırısının İsrail'in hisse senedi ve devlet tahvillerinin volatilitesi ve getirisi üzerindeki etkilerini inceledikleri çalışmalarında, askeri saldırının hisse senedi ve tahvil piyasası üzerinde negatif ve anlamlı etkilerinin olduğu sonucuna ulaşmışlardır. Yine Kollias, Papadamou ve Stagiannis (2011) 11 Mart 2004 Madrid ve 7 Temmuz 2005 Londra bombalı saldırılarının İspanya'nın ve İngiltere'nin yerel borsaları üzerindeki etkilerini inceledikleri çalışmalarında terörist saldırılarının her iki ülkenin finansal piyasaları üzerinde olumsuz etkilerinin olduğu sonucuna ulaşmışlardır. Bouri (2014) savaşın, Orta Doğu ve Kuzey Afrika'daki 12 hisse senedi piyasasının getirisi üzerinde negatif sonuçlara neden olduğu yönünde bulgular elde etmiştir. Apergis vd. (2017) jeopolitik risklerin, 24 küresel savunma firmasının hisse senedi getirileri ve volatilitesi üzerindeki etkilerini incelemek için 1985-2016 dönemi verileri ile doğrusal olmayan nedensellik testi kullanmışlardır. Çalışmada, bu savunma şirketlerinin jeopolitik risk ölçüsünden kaynaklanan hisse senedi getirilerinin tahmin edilebilirliğine yönelik bir bulgu elde edilememiştir. Ancak jeopolitik risk endeksi bu şirketlerin \%50'sinin hisse senetlerindeki oynaklığı öngörmektedir. Ayrıca çalışmadan elde edilen bulgulara göre, küresel jeopolitik olayların belirli bir süre içinde getiriler üzerindeki etkisini öngörme olasıllğı düşük olmasına rağmen, bu küresel riskler savunma firmalarının gelecekteki risk profillerini etkileme eğilimindedir. Akdağ, Yıldırım ve Kesebir (2019) farklı büyüklükte ekonomi ve finansal piyasaya sahip oniki ülkede jeopolitik risklerin borsa endeksi üzerindeki etkisini incelemişlerdir. Kasım 1997 ile Ekim 2018 döneminin analiz edildiği çalışmanın bulguları jeopolitik risk endekslerinden borsa endeksine doğru bir nedenselliğin olduğu ve jeopolitik risk endekslerinde meydana gelen artışların borsa endekslerinde düşüşlere neden olduğu yönündedir. Çam'ın (2014) politik riskin İstanbul Menkul Kiymetler Borsası'na kayıtlı firmaların değerleri üzerindeki etkisini incelediği çalışması 2000-2009 yıllarını kapsamaktadır. Çalışmadan elde edilen bulgulara göre, politik riskin artması firma değerini azaltmaktadır. Kara ve Karabıyık (2015) ülke risk pirimlerinin hisse senedi fiyatları üzerindeki etkisini inceledikleri çalı̧̧malarında, ekonomik, finansal, politik ve ülke risk pirimlerinin hisse senedi fiyatlarını olumsuz yönde etkilediğini ve risk primlerinden hisse senedi fiyatlarına doğru kısa ve uzun dönemli nedenselliğin olduğu yönünde bulgular elde etmişlerdir. Bezgin (2019), Türkiye'de 2009-2018 dönemi için jeopolitik risk endeksinin hisse senedi getirileri üzerindeki etkisi incelemiştir. Çalışmadan elde edilen bulgulara göre, Türkiye'nin jeopolitik risk düzeyi Borsa İstanbul 100, Sınai, Mali, Hizmet ve Teknoloji 
endekslerinin getirileri üzerinde negatif yönde bir etkiye sahiptir. Jeopolitik risk endeksinde meydana gelen 1 birimlik bir artış BIST 100 endeksi getirilerini \%4 oranında azaltmaktadır. Kamışlı (2018), Borsa İstanbul'da yer alan 18 alt sektör endeks getirisi ile Türkiye'nin Jeopolitik Risk Endeksi arasındaki ilişkiyi frekansta nedensellik testi ile analiz etmiştir. Çalışmada sektörler bazında farklı sonuçlar elde edilse de tüm sonuçlar birlikte değerlendirildiğinde, jeopolitik riskin genel olarak alt sektör endeksi üzerinde etkili olduğu sonucuna ulaşılmıştır. İltaş, Arslan ve Kayhan'a (2017) göre jeopolitik riskler ve ülke riski hisse getirilerini düşürmektedir.

Literatürde bazı çalışmalar ise terörizmin finansal piyasalar üzerinde olumsuz etkisine dair kesin bir kanıtın olmadığını savunmaktadırlar. Bu çalışmalara göre, genellikle finansal piyasalar çok etkili ve esnek oldukları için bu tür saldırıların etkisini çok hızlı absorbe edebilmektedirler. Chen ve Siems (2004), 1915'e kadar uzanan süre içerisinde 14 terörist ve askeri saldırının etkilerini inceledikleri çalışmalarında, ABD finansal piyasalarının esnek ve likit olması nedeniyle bu tür saldırıların etkilerini diğer ülkelere nazaran daha hızlı toparlandığını savunmaktadırlar. Çalışmada, mali piyasaların 11 Eylül'e tepkisinin geçmişte yaşanan terörist olaylardan daha az şiddetli olduğu dolayısıyla piyasaların bu etkileri kısa sürede düzelttiği vurgulanmaktadır.

\section{VERI SETI VE AMPÍRIKK MODEL}

$\mathrm{Bu}$ çalışma gelişmekte olan ülkelerde jeopolitik risk ve borsa endeksi arasındaki nedensellik ilişkisini Aralık 1987-Ağustos 2018 dönemi için araştırmaktadır. Çalışma kapsamında Arjantin, Brezilya, Endonezya, Filipinler, Güney Kore, Malezya, Meksika, Tayland ve Türkiye üzerine inceleme yapılmıştır. Jeopolitik risk ve borsa endeksi arasındaki ilişkiyi konu edinen mevcut literatüre göre jeopolitik risk, borsa endeksinde değişmelere yol açacak önemli bir değişkendir. Ancak jeopolitik risk düzeyinde ortaya çıkacak değişimin etkisi, takip eden dönemde borsa endeksi üzerinde gözlenecektir. Bu bağlamda çalışma kapsamında jeopolitik risk endeksini etkileyen bir olayın gecikmeli olarak borsa endeksinde ortaya çıkacak değişmelerin nedeni olup olmadığı sınanacaktır. Jeopolitik risk ve borsa endeksi arasındaki nedensellik ilişkisine yönelik fonksiyonel ilişki şu şekilde ifade edilebilir.

$$
\left[L B O R S A_{t}=f\left(L_{R I S K_{t-1}}\right)\right]
$$

Literatürde jeopolitik risk ile borsa arasındaki nedensellik ilişkisini irdeleyen çalışmalarda endeksteki dalgalanmalar, getiri veya endeks değeri kullanılmaktadır. Bu çalışmada LBORSA ile ifade edilen borsa endeksi değişkeni, ABD doları cinsinden günlük kapanış değerlerini yansıtmaktadır. $\mathrm{Bu}$ değişkene ait veriler Morgan Stanley Capital International (MSCI) resmi internet sitesinden derlenmiştir. LRISK ise Caldara ve Iacoviello (2016) tarafından geliştirilen jeopolitik risk endeksini (GPR) göstermektedir. Bu indeks, jeopolitik tehdit, nükleer tehdit, savaş tehlikesi, terörist tehdit, savaş ve terör faaliyetlerini dikkate alan kapsamlı bir jeopolitik risk ölçütüdür. İlk dört kategori jeopolitik risk ve gerilimlerle bağlantılı iken son ikisi jeopolitik olay ve faaliyetlerle ilgilidir (Caldara ve Iacoviello, 2018: 8). $\mathrm{Bu}$ endekse ilişkin verilere https://www2.bc.edu/matteoiacoviello/gpr.htm internet adresinden erişilmiştir. 
Caldara ve Iacoviello (2016) GPR endeksini geliştirmek için Saiz ve Simonsohn (2013) ile Baker, Bloom ve Davis (2016)'in öncülüğünü yaptığ yöntemden faydalanmışlardır. $\mathrm{Bu}$ doğrultuda $\mathrm{ABD}$, İngiltere ve Kanada'nın önde gelen uluslararası nitelikteki 11 gazetede yayınlanan jeopolitik risk ile alakalı makalelerin sıklığını sayarak bir algoritma geliştirmişlerdir. 1985 yllından başlamak üzere aylık olarak hesaplanan bu endeks, 11 gazetenin elektronik arşivlerinin otomatik metin taraması ile incelenmesi sonucu oluşturulmaktadır. Bu gazeteler içinde The Boston Globe, the Chicago Tribune, The Daily Telegraph, the Financial Times, The Globe and Mail, The Guardian, the Los Angeles Times, The New York Times, The Times, The Wall Street Journal ve the Washington Post yer almaktadır. Endeks değerleri, jeopolitik riskle ilgili haber sayısının toplam yayınlanan makale sayısına oranını göstermektedir. 2000-2009 döneminde ortalama 100 değerine normalize edilen endekse göre 200 olan jeopolitik risk endeksi, ilgili ayda jeopolitik riskle ilgili haberlerin 2000'li yılların iki katı arttığı şeklinde yorumlanmalıdır.

GPR endeksi Arjantin, Brezilya, Çin, Endonezya, Filipinler, Güney Afrika, Güney Kore, Hindistan, İsrail, Kolombiya, Malezya, Meksika, Rusya, Suudi Arabistan, Tayland, Türkiye, Ukrayna ve Venezuela olmak üzere toplamda 18 ülkeye ait data yayınlanmaktadır. Ancak MSCI resmi internet sitesinden alınan borsa endeksi değişkeninin Çin, Hindistan, İsrail, Kolombiya ve Güney Afrika için 1992 yılı Aralık ayından; Rusya için 1994 yılı Aralık ayından; Ukrayna için 2006 yılı Mayıs ayından ve Suudi Arabistan için 2014 yılı Ağustos ayında baş̧ladığı için veri eksikliğine neden olacağı gerekçesiyle bu ülkeler inceleme dışında bırakılmıştır. Venezuela'ya ait borsa endeksi verilerin 2008 yılı Ocak ayında sona ermesinden ötürü bu ülke de analiz dışında tutulmuştur. Amririk analiz kesintisiz verisine erişilebilen en kapsamlı zaman dilimi olan Aralık 1987-Ağustos 2018 periyodu için Arjantin, Brezilya, Endonezya, Filipinler, Güney Kore, Malezya, Meksika, Tayland ve Türkiye üzerine yapılmıştır.

Tablo 1. Jeopolitik Risk Endeksine Ait Tanımlayıcı İstatistikler

\begin{tabular}{|c|c|c|c|c|c|c|c|c|c|}
\hline & Arjantin & Brezilya & Endonezya & Filipinler & G. Kore & Malezya & Meksika & Tayland & Türkiye \\
\hline Ortalama & 4.640 & 4.589 & 4.301 & 4.548 & 4.651 & 4.505 & 4.569 & 4.532 & 4.690 \\
\hline Medyan & 4.646 & 4.608 & 4.286 & 4.536 & 4.635 & 4.497 & 4.5407 & 4.503 & 4.675 \\
\hline Maksimum & 5.769 & 5.387 & 5.668 & 5.398 & 5.646 & 5.653 & 5.297 & 5.750 & 5.767 \\
\hline Minimum & 3.644 & 3.734 & 3.065 & 3.120 & 3.669 & 3.171 & 4.027 & 3.586 & 3.754 \\
\hline Std. Sapma & 0.360 & 0.272 & 0.390 & 0.360 & 0.342 & 0.352 & 0.226 & 0.367 & 0.352 \\
\hline Basıklık & 0.036 & -0.045 & 0.079 & -0.203 & 0.252 & 0.152 & 0.483 & 0.454 & 0.257 \\
\hline Çarpıklık & 3.122 & 3.572 & 3.176 & 3.096 & 3.188 & 3.873 & 3.072 & 3.458 & 2.843 \\
\hline Jarque-Bera & 0.311 & 5.172 & 0.868 & 2.687 & 4.457 & 13.16 & 14.47 & 15.95 & 4.459 \\
\hline Olasılık & 0.855 & 0.075 & 0.647 & 0.260 & 0.107 & 0.001 & 0.001 & 0.001 & 0.107 \\
\hline Gözlem & 369 & 369 & 369 & 369 & 369 & 369 & 369 & 369 & 369 \\
\hline \multicolumn{10}{|l|}{ Korelasyon } \\
\hline Katsayıs1 & -0.16 & -0.35 & -0.10 & -0.19 & -0.16 & -0.23 & -0.17 & -0.11 & -0.16 \\
\hline
\end{tabular}

Çalışmada incelenen 9 gelişmekte olan ülkenin jeopolitik risk endekslerine ilişkin tanımlayıcı istatistikler Tablo 1'de yer almaktadır. Tablodaki Jarque-Bera istatistiklerine göre jeopolitik risk endeksi Arjantin, Endonezya, Filipinler, Kore ve Türkiye'de \%99 önem düzeyinde normal dağılıma sahiptir. Serinin normal dağılıma sahip olduğunu belirten boş hipotez Brezilya'da \%90 önem düzeyinde Malezya, Meksika ve Tayland'da ise \%99 önem düzeyinde reddedilmektedir. 
İki değişken arasındaki ilişkinin yönü hakkında bilgi veren korelasyon matrisi incelendiğinde ise analize dahil edilen 9 ülkenin tamamından jeopolitik risk ve borsa endeksi arasında negatif yönlü bir korelasyon olduğu tespit edilmiştir. Ancak iki değişken arasındaki nedensellik ilişkisinin tespiti için nedensellik yöntemlerine ihtiyaç duyulmaktadır.

\section{EKONOMETRİK YÖNTEM VE AMPİRIK BULGULAR}

Panel veri analizlerinde nedensellik ilişkisinin varlığını test etmek üzere pek çok yöntem geliştirilmiştir. Bunlardan Panel VECM (vektör hata düzeltme modeli) ve Canning ve Pedroni (2008), yatay kesit bağımlılığı dikkate almayan ve aynı zamanda aralarında nedensellik ilişkinin araştırılacağı değişkenlerin uzun dönemde eşbütünleşik olmalarını gerektiren yöntemlerdir. Eşbütünleşme ilişkisi gerektirmeyen Dimitrescu ve Hurlin (2012) ve Emirmahmutoğlu ve Köse (2011) yöntemleri ise panelin heterojen yapısını dikkate almasına rağmen yatay kesit bağımlılığını göz önünde bulundurmamaktadır. Kónya (2006) bootstrap nedensellik testi ise yatay kesit bağımlılı̆g ve hetorojenlik koşullarında kullanılabilecek en uygun yöntem olmaktadır.

Yatay kesit bağımlılığını test etmek amacıyla geliştirilen yöntemler yatay kesit birimi ve zaman diliminin boyutuna göre çeşitlenmektedir. Bu çalışmada olduğu gibi zaman boyutunun yatay kesit boyutundan büyük olduğu panellerde Breusch ve Pagan (1980) LM, Pesaran (2004) $C D_{L M}$ ve Pesaran vd. (2008) $L M_{a d j .}$ testlerinden yararlanılmaktadır.

Zaman diliminin yatay kesit boyutundan oldukça büyük olduğu durumlarda kullanılan Breusch ve Pagan (1980) $L M$ testi asimtotik ki-kare dağılımına sahip iken Pesaran (2004) $C D_{L M}$ yöntemi normal dağılım göstermektedir. Standart normal dağılıma sahip bir diğer

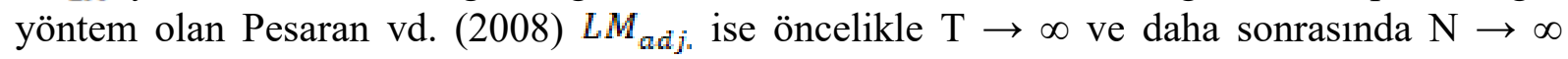
olduğu durumlarda anlamlı sonuçlar vermektedir. $L M_{,} C D_{L M}$ ve $L M_{\text {adj. }}$ test istatistikleri sırasıyla Eşitlik 2, 3 ve 4 kullanılarak elde edilmektedir.

$$
\begin{aligned}
& L M=T \sum_{i=1}^{N-1} \sum_{j=i+1}^{N} \hat{\rho}_{i j}^{2} \\
& C D_{L M}=\sqrt{\frac{1}{N[N-1)}} \sum_{i=1}^{N-1} \sum_{j=i+1}^{N}\left(T \hat{P}_{i j}^{2}-1\right) \\
& L M_{\text {adj }}=\sqrt{\frac{2}{N[N-1)}} \sum_{d_{i=1}^{N-1}}^{N} \sum_{j=i+1}^{N} \frac{(T-\hat{N}) \hat{P}_{i j}^{2}-\mu_{T i j}}{\theta_{T i j}}
\end{aligned}
$$

Değişkenlerin eğim katsayılarının homojenliğini test etmek için Pesaran ve Yamagata (2008) tarafından Delta testi geliştirilmiştir. Delta testi, boş hipotezde eğim katsayının homojen olduğunu, alternatif hipotezde ise heterojen olduğu savını sınamaktadır. Bu yönteme göre büyük panellerde $\widetilde{\Delta}$ (Eşitlik 5); küçük panellerde ise $\widetilde{\Delta}_{\text {adj, }}$ istatistiğine (Eşitlik 6) ait 
olasılık değerinin $\% 5$ önem düzeyinde 0.05 'ten daha büyük olması durumunda boş hipotez reddedilecek ve panele ait eğim katsayısının homojenliğine karar verilecektir.

$$
\begin{aligned}
& \hat{\Delta}=\sqrt{N}\left(\frac{N^{-1} \tilde{s}-k}{\sqrt{2 k}}\right) \\
& \tilde{\Delta}_{a d j .}=\sqrt{N}\left(\frac{N^{-1} \tilde{s}-E\left(\tilde{\mathbb{Z}}_{T T}\right.}{\sqrt{\operatorname{var} \tilde{Z}_{T T}}}\right)
\end{aligned}
$$

Tablo 2'de raporlanan yatay kesit bağımlılı̆̆ test sonuçlarına göre jeopolitik risk ve borsa endeksi değişkenlerinde yatay kesit bağımsızlı̆ı olduğunu belirten boş hipotez \%99 önem düzeyinde reddedilmektedir. Homojenlik test sonuçları incelendiğinde ise eğim katsayılarının homojen olduğunu test eden boş hipotezin kabul edilmediği ve panelin heterojen özellik taşıdığı görülmüş̧ür. Bu bulgu panelin heterojen yapıda olduğunu ortaya koymaktadır.

Tablo 2. Yatay Kesit Bağımlılı̆̆ı ve Homojenlik Testi Sonuçları

\begin{tabular}{lccccc}
\hline & \multicolumn{3}{c}{ Yatay Kesit Bağımlılı̆̆ Testi } & \multicolumn{2}{c}{ Homojenlik Testi } \\
\hline Değişken & $L M$ & $C D_{L M}$ & $L M_{a d j_{0}}$ & $\varangle$ & $\Xi_{\text {adj. }}$ \\
LRISK & $920.288^{*}$ & $104.214^{*}$ & $104.202^{*}$ & $2.5531^{* *}$ & $2.5635^{* *}$ \\
LBORSA & $5487.267^{*}$ & $642.4380^{*}$ & $642.4258^{*}$ & & \\
\hline
\end{tabular}

Not: * yatay kesit bağımlılı̆̆ının olmadığını belirten boş hipotezin; ** ise eğim katsayılarının homojen olduğunu belirten boş hipotezin \%99 önem düzeyinde reddedildiğini göstermektedir.

Heterojen yapıda olduğu ve yatay kesit bağımlılığının varlığı tespit edilen panelde jeopolitik risk ve borsa endeksi arasındaki nedensellik ilişkisinin araştırılmasında Kónya (2006) bootstrap panel nedensellik yönteminden yararlanılmıştır. Yatay kesit bağımlılığını ve heterojenliği dikkate alan bu yöntem, diğer nedensellik yöntemlerinde olduğu gibi VAR yerine Zellner (1962) tarafından geliştirilen SUR (Seemingly Unrelated Regressions) tahmincisine dayanmaktadır. Bu yöntem ayrıca aralarında nedensellik ilişkisi araştırılacak değişkenlerin durağan olmalarına yönelik bir ön koşul gerektirmemekte ve bu nedenle değişkenlerin seviye değerleri ile analiz yapılmaktadır (Kónya, 2006: 981).

Kónya (2006) Bootstrap panel nedensellik testi 5 aşamalı bir süreç izlenerek uygulanmaktadır (Kónya, 2006: 985). Birinci aşamada Eşitlik X'de verilen modeller tahmin edilerek hata terimlerine ulaşılır. Eşitliklerde $N$ ülke sayısını, $t$ ülke sayısını, $l$ gecikme uzunluğunu, $\varepsilon$ ise hata terimini ifade etmektedir. Elde edilen hata terimlerinden hareketle $N x T\left[e_{H o, i, t}\right]$ matriksi oluşturulur (Kónya, 2006: 981).

$$
\begin{aligned}
& y_{1, t}=\alpha_{1,1}+\sum_{l=1}^{m l y_{1}} \beta_{1,1, l} y_{1, t-1}+\sum_{l=1}^{m l x_{1}} \gamma_{1,1, l} x_{1, t-1}+\varepsilon_{1,1, t} \\
& y_{2, t}=\alpha_{1,2}+\sum_{l=1}^{m l y_{1}} \beta_{1,1, l} y_{1, t-1}+\sum_{l=1}^{m l x_{1}} \gamma_{1,1, l} x_{1, t-1}+\varepsilon_{1,1, t}
\end{aligned}
$$




$$
y_{N_{l} t}=\alpha_{1, N}+\sum_{l=1}^{m l y_{1}} \beta_{1, N, l} y_{N_{l}, t-1}+\sum_{l=1}^{m l x_{1}} \gamma_{1, N_{l} l} x_{N_{l}, t-1}+\varepsilon_{1, N_{l}, t}
$$

İkinci aşamada hata terimleri yeniden örneklendirilir. Eşitlik 2'deki hata terimlerinin yatay kesit bağımlılığı özelliğini korumak için her bir ülkenin hata terimini tek tek çekmek yerine $\left[e_{H_{o, i, t}}\right]$ matriksinden tesadüfi olarak tüm bir sütun alınır. Seçilen bootstrap hata terimleri, $t=1, \ldots, T^{*}$ ve $T^{*}>T$ olmak üzere $\varepsilon_{H o_{0}, \text {, }}^{*}$ olarak tanımlanır. Üçüncü aşamada Eşitlik 3'te verilen formülden hareketle X'in Y'nin nedeni olmadığı varsayımı ile bootstrap örneklemi oluşturulur.

$$
y_{i_{2} t}^{*}=\hat{\alpha}_{1_{i}, i}+\sum_{i=1}^{m l_{y_{1}}} \hat{\beta}_{1_{i}, i l} y_{i_{i}, t-1}^{*}+\varepsilon_{H o_{i}, t}^{*}
$$

Dördüncü aşamada ise hiçbir parametre kısıtı olmaksızın Eşitlik 1'de $y_{i, t}$ yerine $y_{i, t}^{*}$ konulur ve her bir ülke için nedenselliğin olmadığını belirten boş hipotezi test etmek için Wald testi uygulanır. Beşinci ve son aşamada ise 2, 3 ve 4. aşamalar defalarca tekrarlanarak Wald test istatistiğinin dağılımı geliştirilir. Sonrasında örnek dağılımda uygun yüzdelik dilimler seçilerek bootstrap kritik değerleri belirlenir.

$\mathrm{Bu}$ yönteme göre her bir ülke için hesaplanan Wald istatistiğinin, incelenen önem düzeyinde bootstrap kritik değerlerinden büyük olması durumunda nedenselliğin olmadığını belirten boş hipotez reddedilecektir. Bir diğer ifadeyle Wald istatistiğinin bootstrap kritik değerden büyük olması, bağımsız değişkenden bağımlı değişkene doğru bir nedensellik olduğunu gösterecektir.

Tablo 3. Kónya (2006) Panel Nedensellik Testi Sonuçları

\begin{tabular}{lcccc}
\hline Ülke & Test & \multicolumn{3}{c}{ Bootstrap ktirik değerler } \\
\cline { 3 - 5 } & istatistiği & $\% 1$ & $\% 5$ & $\% 10$ \\
\hline Arjantin & $8.2403^{*}$ & 15.0166 & 8.7144 & 5.9791 \\
Brezilya & $8.3519^{* *}$ & 14.3346 & 8.2292 & 5.4210 \\
Endonezya & 0.6752 & 16.3245 & 10.7354 & 7.0306 \\
Filipinler & 0.5723 & 11.0698 & 7.0333 & 4.8499 \\
Kore & 0.3996 & 14.7713 & 8.2742 & 5.1665 \\
Malezya & 0.9259 & 12.6409 & 7.3938 & 5.1826 \\
Meksika & $6.5192^{*}$ & 16.5826 & 9.0903 & 6.0750 \\
Tayland & $7.2665^{*}$ & 15.1673 & 8.5387 & 6.0550 \\
Türkiye & 0.8224 & 12.3401 & 7.9047 & 5.7086 \\
\hline
\end{tabular}

Not: ** ve * boş hipotezin sırasıyla $\% 95$ ve 90 önem düzeyinde reddedildiğini göstermektedir. Boş hipotez: LRISK, LBORSA'nın nedeni değildir.

Tablo 3'de yer alan nedensellik testi sonuçları "LRISK, LBORSA'nın nedeni değildir" boş hipotezinin Brezilya'da \%95 önem düzeyinde, Arjantin, Meksika ve Tayland'da ise \%90 önem düzeyinde reddedildiğini göstermektedir. Bu sonuca göre incelenen 9 gelişmekte olan ülkeden Arjantin, Brezilya, Meksika ve Tayland'da jeopolitik riskler, borsa endeksinin nedeni olmaktadir. 


\section{SONUÇ}

Piyasa sistemine dayalı ekonomilerde borsalar, ekonomik, sosyal ve politik yaşamın bir barometresi olarak çalışmaktadırlar. Ekonomik, sosyal ve politik hayattaki tüm değişmeler, gelişmeler ve problemler finansal piyasalar tarafından fiyatlanmaktadır. Nükleer tehdit, savaş tehlikesi, terör olayları gibi politik risk unsurları finansal piyasalar için önemli bir belirsizlik unsuru oluşturmaktadır. Bu belirsizlik, kaynak ihtiyacını karşılayan finansal piyasalar için risk düzeyini artırarak olumsuz etki yaratmaktadır. Risk unsurlarının arttığ1 dönemlerde yatırımcılar hisse senedi gibi yatırım araçlarından ziyade riskin daha az olduğu hazine bonosu ve altın gibi yatırım araçlarına yönelmektedirler. Jeopolitik riskin diğer bir etkisi ise volatilite (oynaklık) üzerinde oluşturduğu etkidir. Jeopolitik risk unsurundaki değişimler, finansal bir ürünün fiyatının belirli zamanlar içerisinde dalgalanmalar göstermesine neden olmaktadır. Dolayısıyla jeopolitik risk bileşenleri hem borsa getirileri hem de volatilite üzerinde etkilidir. Dahası küresel sermaye piyasalarının birbiri ile sıkı bir ilişki içerisinde olması terör olayları, savaş ve terör tehdidi gibi jeopolitik risk haberlerinin hisse senedi fiyatlarında oluşturacağ 1 ekonomik etki "bulaşma etkisi" ile diğer ülkelerin finansal piyasalarını da etkileyebilecektir.

$\mathrm{Bu}$ çalışmada, Arjantin, Brezilya, Endonezya, Filipinler, Güney Kore, Malezya, Meksika, Tayland ve Türkiye için jeopolitik risk ve borsa endeksi arasındaki nedensellik ilişkisi Aralık 1987-Ağustos 2018 dönemi için incelenmektedir. Çalışmada, Caldara ve Iacoviello (2016) tarafından geliştirilen jeopolitik risk endeksi (GPR) kullanılmaktadır. Bu indeks, jeopolitik tehdit, nükleer tehdit, savaş tehlikesi, terörist tehdit, savaş ve terör faaliyetlerini dikkate alan kapsamlı bir jeopolitik risk ölçütüdür. Çalışmadan elde edilen bulgulara göre, Arjantin, Brezilya, Meksika ve Tayland'da jeopolitik riskler, borsa endeksinin nedeni olmaktadır. Bu sebeple piyasayı istikrarlı hale getirmeye yardımcı olabilecek güçlü bir finansal yapının ve ülkeye özgü riskleri çeşitlendirmeyi sağlayacak bir ekonomik sistemin oluşturulması oldukça önemlidir.

\section{KAYNAKLAR}

Abadie, Alberto - Gardeazabal, Javier (2003), "The Economic Costs of Conflict: A Case Study Of The Basque Country”, American Economic Review, 93, 1, pp. 113-132.

Aksoy, Ahmet - Tanrı̈ven, Cihan (2013), Sermaye Piyasası Yatırım Araçları ve Analizi, 4. Bask1, Detay Yayıncılık, Ankara.

Akdağ, Saffet - Yıldırım, Hakan - Kesebir, Murat (2019), Jeopolitik Risk ile Borsa Endeksleri Arasındaki İlişki: Panel Eşbütünleşme ve Panel Nedensellik Analizi, İnanır, Emine Köse, Osman - Ulutürk, Yasemin (Ed) Siyasi, Sosyal ve Kültürel Yönleriyle Türkiye ve Rusya 2 içinde, Berikan Yayınevi, Ankara. ss.59-74.

Apergis, Nicholas - Bonato, Matteo - Gupta, Rangan - Kyei, Clement (2017), "Does Geopolitical Risks Predict Stock Returns and Volatility of Leading Defence Companies? Evidence from a Nonparametric Approach", Defence and Peace Economics, 29, 6, pp.684-696. 
Arin, K.Peren - Ciferri, Davide - Spagnolo, Nicola (2008), "The Price of Terror: The Effects of Terrorism on Stock Market Returns and Volatility", Economics Letters, 101,3, pp. 164-167.

Aslam, Faheem - Kang, Hyoung Goo (2015)," How Different Terrorist Attacks Affect Stock Markets", Defence and Peace Economics, 26, 6, pp. 634-648.

Baker, R. Scott - Bloom, Nicholas - Davis, J.Steven (2016), "Measuring Economic Policy Uncertainty", The Quarterly Journal of Economics, 131, 4, pp.1593.

Balcilar, Mehmet - Gupta, Rangan - Pierdzioch, Christian - Wohar, Mark E. (2016), "Terror Attacks and Stock- Market Fluctuations: Evidence Based on a Nonparametric Causality-in-Quantiles Test for the G7 Countries", European Journal of Finance, 24,4, pp.333-346.

Balcilar, Mehmet - Cerci, Gözde - Demirer, Rıza (2016), “Is There a Role for Islamic Bonds in Global Diversification Strategies?”, Managerial Finance, 42, 7, pp. 656-679.

Balc1lar, M., M. Bonato, R. Demirer ve R. Gupta, (2018). Geopolitical Risks and Stock Market Dynamics of the BRICS. Economic Systems, 42, 295-306.

Bezgin, Müge Sağlam (2019), “Türkiye'nin Jeopolitik Riski’nin Borsa İstanbul Endeks Getirileri Üzerine Etkisinin İncelenmesi”, 18th International Business Congress, ss. 2565-2574.

Breusch, T.S. - Pagan, Adrian (1980), “The Lagrange Multiplier Test And Its Application to Model Specifications in Econometrics", Reviews of Economics Studies, 47, pp. 239253.

Bouri, Elie I. (2014), "Israeli-Hezbollah War and Global Financial Crisis in the Middle East and North African Equity Markets", Journal of Economic Integration, 29, pp.1-19.

Caldara, Dario - Iacoviello, Matteo (2018), "Measuring Geopolitical Risk", Working Paper, Board of Governors of the Federal Reserve Board, https://www2.bc.edu/matteo-iacoviello/gpr_files/GPR_PAPER.pdf (Erişim tarihi: 07.10.2018)

Canning, David - Pedroni, Peter (2008), "Infrastructure, Long-Run Economic Growth And Causality Tests For Cointegrated Panels", The Manchester School, 76, 5, pp. 504-527.

Charles, Amelie - Darné, Oliver (2006), "Large Shocks and the September 11th Terrorist Attacks on International Stock Markets", Economic Modelling, 23, pp. 683-698.

Chen, Andrew H. - Siems, F. Thomas (2004), "The Effects of Terrorism on Global Capital Markets”, $\quad$ European Journal of Political Economy, 20, pp. 349-366.

Çam, Alper Veli (2014), “Politik Riskin Firma Değeri ile İlişkisi: IMKB’ye Kayıtlı Firmalar Üzerinde Bir Uygulama”, Doğuş Üniversitesi Dergisi, 15, 1, ss.109-122. 
Drakos, Konstantinos (2010), "Terrorism Activity, İnvestor Sentiment and Stock Returns", Review of Financial Economics, 19, 3, pp.128-135.

Dumitrescu, Elena-Ivona - Hurlin, Christophe (2012), "Testing for Granger Non-Causality in Heterogeneous Panels", Economic Modelling, 29, pp. 1450-1460.

Emirmahmutoglu, Furkan - Kose, Nezir (2011), "Testing for Granger Causality in Heterogeneous Mixed Panels", Economic Modelling, 28, pp. 870-876.

İltaş, Yüksel - Arslan, Halil - Kayhan, Temur (2017), "The Stock Return Predictability: Comparing P/E and EV/EBITDA", Journal of Economics, Finance and Accounting (JEFA), 4, 3, pp. 262-274.

Kamışl1, Melik (2018), Jeopolitik Risk ve Hisse Senedi Getirileri: Sektörel Yaklaşım, Temizel, Fatih (edt.), İşletme ve Finans Yazıları - I içinde, Beta Basım Yayım Dağıtım, İstanbul, ss. 291-313.

Kara, E. Ve Karabıyı, L. (2015). Ülke Riskinin Hisse Senedi Fiyatlarına Etkisi: Borsa İstanbul'da Bir Uygulama, Süleyman Demirel Üniversitesi İktisadi ve İdari Bilimler Fakültesi Dergisi, 20(1), 225-239.

Karolyi, G.Andrew - Martell, Rodolfo (2010), "Terrorism and the Stock Market", International Review of Applied Financial Issues and Economics, 2,2, pp. 285314.

Kollias, Christos - Papadamou, Stephanos - Stagiannis, Apostolos (2010), "Armed Conflicts and Capital Markets: The Case of the Israeli Military Offensive in the Gaza Strip", Defence and Peace Economics, 21, 4, pp. 357-365.

Kollias, Christos - Papadamou, Stephanos - Stagiannis, Apostolos (2011), "Terrorism and Capital Markets: The Effects of the Madrid and London Bomb Attacks", International Review of Economics and Finance, 20, 4, pp. 532-541.

Kollias, Christos - Kyrtsou, Catherine - Papadamou, Stephanos (2013), "The Effects of Terrorism and War on the Oil Price-Stock Index Relationship", Energy Economics, 40, pp.743-752.

Kónya, Laslo (2006), "Exports and Growth: Granger Causality Analysis on OECD Countries with a Panel Data Approach", Economic Modelling, 23, pp.978-992.

Pesaran, M. Hashem - Ullah, Aman - Yamagata, Takashi (2008), “A Bias-Adjusted LM Test of Error Cross-Section Independence", Econometrics Journal, 11, pp.105-127.

Pesaran, M. Hashem - Yamagata, Takashi (2008), "Testing Slope Homogeneity in Large Panels", Journal of Econometrics, 142,1, pp. 50-93.

Pesaran, M. Hashem (2004), "General Diagnostic Tests for Cross Section Dependence in Panels", CESifo Working Paper 1229; IZA Discussion Paper 1240. 
Saiz, Albert - Simonsohn, Uri (2013), "Proxying For Unobservable Variables With Internet Document-Frequency", Journal of the European Economic Association, 11,1, pp.137165 .

Zellner, Arnold (1962), “An Efficient Method of Estimating Seemingly Unrelated Regressions and Tests For Aggregation Bias", Journal of the American Statistical Association, 57, pp. 348-368.

Zussman, Asaf - Zussman, Noam (2006), “Assassinations: Evaluating the Effectiveness of an Israeli Counterterrorism Policy Using Stock Market Data", The Journal of Economic Perspectives, 20, 2, pp. 193-206. 
